\title{
Revaloración del patrimonio edificado a través del color. El caso de Jala, Nayarit (México) ${ }^{1}$
}

\author{
Revaluation of built heritage through color. \\ The case of Jala, Nayarit (Mexico)
}

\section{Cómo citar:}

Escobedo Hernández, J., 2020. Revaloración del patrimonio edificado a través del color. El caso de Jala, Nayarit (México). Designia, 8(1), pp.121-141.

\author{
${ }^{1}$ Este trabajo es el resultado de la colaboración interinstitucional \\ que lleva a cabo el Centro INAH Nayarit, como parte de las acciones \\ encaminadas a la protección técnica y legal de los monumentos \\ históricos de la entidad. \\ * Licenciado en Arquitectura y Maestro en Ordenamiento Urbano \\ por el Instituto Tecnológico de Tepic (México) y Máster \\ en Restauración y Rehabilitación del Patrimonio por \\ la Universidad de Alcalá de Henares (España). \\ E-mail: jorge_escobedo@inah.gob.mx \\ ORCID: https://orcid.org/0000-0002-8605-4215
}

Palabras clave:

Patrimonio edificado, paisaje, conservación de monumentos

Key words:

Built heritage, landscape,

preservation of monuments

Recibido: $11 / 03 / 2020$

Aceptado: 07/05/2020

Resumen:

El presente trabajo de investigación documenta, desde un enfoque cualitativo, el proceso que se siguió para la elaboración de una propuesta cromática para la localidad de Jala, México; estos trabajos fueron coordinados por el Centro INAH Nayarit.

El objetivo principal fue contribuir en la conservación del patrimonio edificado con que cuenta esta población, a través de la recuperación de la gama de colores que tuvieron sus fachadas entre finales del siglo XIX y principios del XX, además de involucrar a los habitantes en un proceso de revaloración de este patrimonio. 
La metodología y herramientas empleadas tuvieron cuatro pilares: la elaboración de calas estratigráficas, la búsqueda de información historiográfica, la conformación de un equipo multidisciplinario e interdisciplinario $\mathrm{y}$, finalmente, incluir a la ciudadanía, tanto para la toma de decisiones como en la ejecución de los trabajos; estos pilares se pueden ver a través de los ocho pasos que conforman dicha metodología, los cuales se detallarán en los párrafos subsecuentes.

Los resultados de llevar a cabo lo anterior demuestran que la forma más efectiva que se tiene para que la gente se involucre de manera activa en la conservación de su patrimonio es valorándolo, y en este caso, la valoración parte de reconocer su arquitectura como patrimonial y la cromática como parte fundamental de esa arquitectura.

\section{Abstract:}

This investigation documents, from a qualitative approach, the process that was followed for the elaboration of a chromatic proposal for the town of Jala, in Mexico; these works were coordinated by the INAH Nayarit Centre.

The main objective was to contribute to the conservation of the built heritage of this population, through the recovery of the range of colors that had its facades in the late nineteenth and early twentieth centuries, thus strengthening the identity of its Inhabitants.

The methodology and tools used had four pillars: the development of stratigraphic coves, the search for historiographic information, the formation of a multidisciplinary and interdisciplinary team and, finally, involve the citizens, both for decision-making and for the execution of work; these pillars can be seen through the eight steps that make up this methodology, which are detailed throughout the article.

The results of doing the above show that the most effective way for people to be actively involved in the preservation of their heritage is to value it, and in this case, the valuation part of recognizing its architecture as heritage and to chromaticity as a fundamental part of that architecture. 


\section{INTRODUCCIÓN}

Jala es una pequeña villa de 5,586 habitantes ${ }^{2}$, ubicada en el sureste del estado mexicano de Nayarit y es cabecera del municipio del mismo nombre. Sus orígenes se remontan al siglo XVI con la construcción de un Convento Franciscano dedicado a la Inmaculada Concepción; se trata de una de esas localidades en las que parece que el tiempo se ha detenido, su imagen urbana está dominada por calles empedradas y viviendas hechas con muros de adobe y cubiertas de tejas; aquí la gente se siente muy orgullosa de su Basílica Lateranense, imponente templo parroquial decimonónico dedicado a Nuestra Señora de la Asunción, en torno al cual se han generado diversas manifestaciones culturales; también son famosos sus brujos, su feria y sus fiestas religiosas, sin olvidar que, en esta tierra, se cultivan los elotes más grandes de México (González, 2019).

Dentro de este sincretismo resultante, que engloba aspectos tanto tangibles como intangibles, existen elementos que empiezan a verse amenazados, específicamente su arquitectura vernácula, ya que, entre las nuevas generaciones, se percibe un cambio de paradigma que tiende a considerar a estas viviendas como anticuadas e inseguras, generándose una paulatina pero constante alteración del paisaje urbano, haciendo que las cubiertas de tejas sean sustituidas por losas de concreto armado, y que la intervención de sus muros se haga bajo la premisa de que deben reforzarse con materiales contemporáneos que "garantizan su estabilidad".

Ante este escenario destructivo, surge la necesidad de establecer estrategias que permitan una resignificación de los valores culturales de la localidad que le son inherentes, promoviendo su rescate; una de las primeras acciones implementadas está relacionada con el uso del color como herramienta para la revaloración de esa arquitectura tradicional, la cual forma parte importante de la identidad de Jala, y que ha permanecido en el imaginario colectivo desde hace siglos. La metodología, alcances y resultados de la puesta en marcha de esta estrategia, son la base para la realización del presente artículo.

${ }^{2}$ Esta cifra corresponde a la población total de la localidad en el año 2010, según datos del XIII Censo General de Población y vivienda, llevado a cabo por el INEGI. 
Patrimonio cultural, algunas definiciones

Una definición básica acerca del término Patrimonio es el que maneja el Diccionario de la Real Academia Española de la Lengua (2014), quien simplemente lo menciona como la hacienda que alguien ha heredado de sus ascendientes. En consecuencia, una parte de esta herencia estaría conformada por el denominado Patrimonio Cultural, término que es precisado y clasificado por la UNESCO (1972), a través de la Convención para la Protección de Patrimonio Mundial, Cultural y Natural, mejor conocida como Convención de París, de la siguiente manera:

- Los monumentos: obras arquitectónicas, de escultura o de pintura monumentales, elementos o estructuras de carácter arqueológico, inscripciones, cavernas y grupos de elementos, que tengan un valor universal excepcional desde el punto de vista de la historia, del arte o de la ciencia.

- Los conjuntos: grupos de construcciones, aisladas o reunidas, cuya arquitectura, unidad e integración en el paisaje les dé un valor universal excepcional desde el punto de vista de la historia, del arte o de la ciencia.

- Los lugares: obras del hombre u obras conjuntas del hombre y la naturaleza, así como las zonas incluidos los lugares arqueológicos que tengan un valor universal excepcional desde el punto de vista histórico, estético, etnológico o antropológico. 
En el caso particular de México, la definición legal del Patrimonio Cultural se encuentra en la Ley Orgánica de la Administración Pública Federal (1976), misma que en su artículo 41 Bis, fracción II, hace alusión a una de las diversas facultades que tiene la Secretaría de Cultura, y que es la de conservar, proteger y mantener los monumentos arqueológicos, históricos y artísticos que conforman el patrimonio cultural de la Nación.

Existen otras concepciones, como la de García (1997, p. 63), quien asegura que el patrimonio cultural [...] no abarca solo los monumentos históricos, el diseño urbanístico y otros bienes físicos; también la experiencia vivida se condensa en lenguajes, conocimientos, tradiciones inmateriales, modos de usar los bienes y los espacios físicos.

Lira (2004, p. 0), por su parte, para su definición toma en cuenta, el significado que tiene o tendrá el bien para la población, llegando a la siguiente conclusión:

\footnotetext{
No es fácil ponerse de acuerdo en qué es patrimonio. El concepto incluso varía con los tiempos: lo que nos parece deleznable hoy, puede ser objeto de culto mañana. Así les debe haber pasado a quienes demolieron tantas casas antiguas, en nombre del progreso, que no ha quedado casi nada que nos atestigüe cómo era la ciudad en otros tiempos.
}

Como se pudo ver, la conformación del patrimonio cultural es multifactorial y puede abracar desde elementos de gran escala, como una pirámide prehispánica, hasta elementos menos imponentes, pero igualmente relevantes, como es el caso del color empleado en una fachada; un caso de este segundo ejemplo será desglosado a continuación. 
La magia de una Villa

Si los colores hablan todos los idiomas, como asegura Joseph Addison (Pereira, 2013), las fachadas serían uno de los fonemas más hermosos creados por el hombre, con los cuales se podrían articular toda clase de palabras y frases, de cuya combinación se conseguirían pueblos pintorescos, como es el caso de la villa de Jala, en México (Ver figura 1).

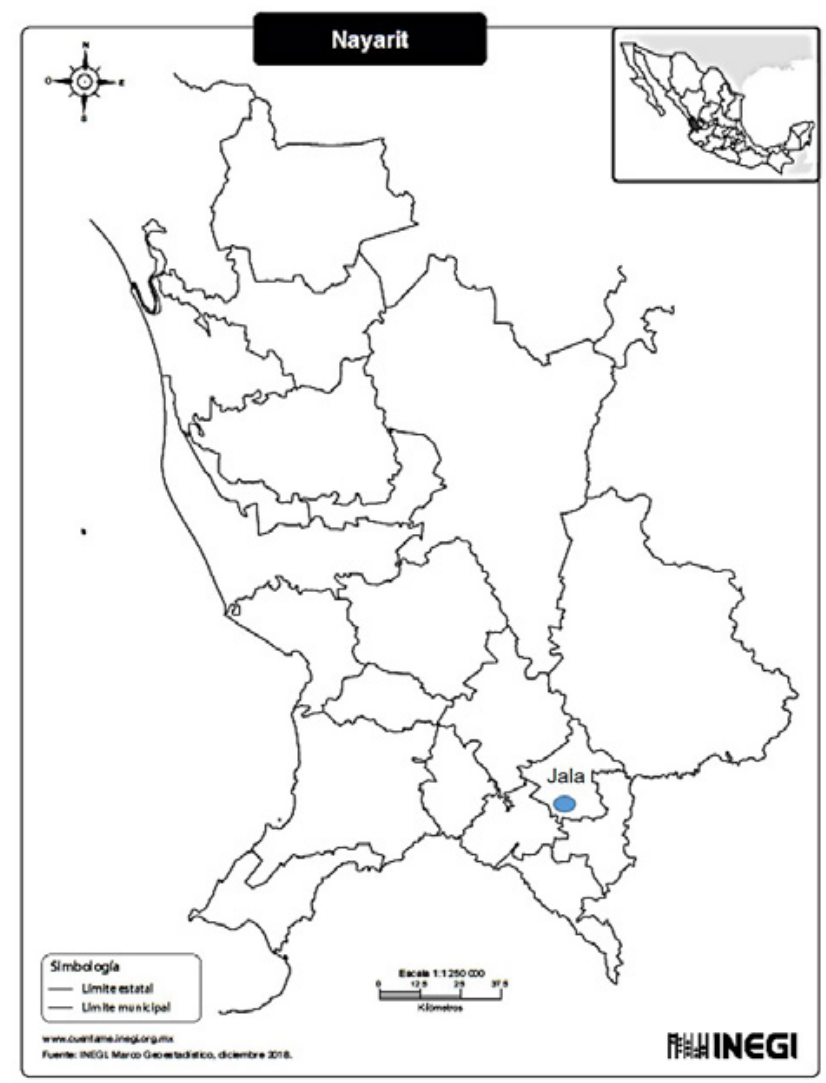

Figura 1. Localización geográfica de Jala. Fuente: Instituto Nacional de Estadística, Geografía e Informática (2018). 
Su origen se remonta al año de 1582 con la construcción de un Convento Franciscano dedicado a la Inmaculada Concepción (González, como se citó en Vite, 2011, p. 8); en torno a este emplazamiento fundacional se edificaron los demás templos y viviendas, con un predominio de la arquitectura vernácula. Dentro de los acontecimientos históricos más relevantes, podemos comentar que al finalizar el siglo XIX aún se explotaban algunos de los minerales de la región, lo que explica el auge que tuvo Xala y el hecho de que se hubieran construido las grandes casas de los ricos (González, 2009, p. 68); de igual manera, el 12 de diciembre de 1912, fue consagrada la Basílica Lateranense de Jala, dedicada a la Señora de la Asunción. La primera piedra fue colocada en 1856 (SEPEN, s.f.a, p. 15). Otro aspecto a destacar fue aquel intento por conservar su patrimonio edificado cuando el 6 de julio [de 1966], el Congreso del Estado emite el decreto 4795, por el cual se declara al pueblo de Jala "Monumento Colonial en el estado, para salvaguardar la pureza del estilo en las construcciones, así como sus tradiciones y el ambiente de provincia colonial que aún conserva" (López, como se citó en Samaniega, 2004, pp. 68-69); vale la pena aclarar que este decreto no fue promulgado por el gobernador Julián Gascón Mercado, en consecuencia, no fue publicado en el Periódico Oficial y por lo tanto no tuvo validez (SEPEN, s.f.b, p. 10).

Dentro de la realidad socioeconómica que prevalece en Jala, y en general en todo el municipio, tenemos lo relacionado al porcentaje de la población que vive en pobreza; se dice que una persona se encuentra en situación de pobreza cuando presenta una o más carencias sociales y no tiene un ingreso suficiente para satisfacer sus necesidades (CONEVAL, s.f., p. 4); estas carencias sociales se refieren a la educación, salud, seguridad social, vivienda, servicios básicos y alimentación; según un estudio de la CONEVAL (2015), el porcentaje de los habitantes del municipio de Jala que se encuentra en ese supuesto es del $70.6 \%$, ubicándolos en el cuarto lugar a nivel estatal, solamente por detrás de los tres municipios de la sierra, Huajicori, Del Nayar y La Yesca, con $88.2 \%$, $86.9 \%$ y $79.4 \%$ respectivamente, mismos que duplican el promedio del estado, el cual es del $38.2 \%$.

Sin duda, y paradójicamente, la situación socioeconómica imperante en la localidad ha sido determinante en el destino de su patrimonio edificado, pues, el elevado nivel de pobreza, ha forzado su conservación; en la actualidad, según el INAH (1994), en este lugar se tienen 243 construcciones con valor patrimonial, razón por la cual, en noviembre de 2012, fue incluida en el programa turístico denominado Pueblos Mágicos, el cual es coordinado por la SECTUR (2019), misma que asegura que este programa contribuye a revalorar a un conjunto de poblaciones del país que siempre han estado en el imaginario colectivo de la nación y que representan alternativas frescas
${ }^{3}$ Existe cartografía y documentación histórica en la que aparece el nombre de la localidad como Xala, desconociéndose la fecha exacta en la que se dio el cambio a Jala, tal y como se conserva hasta nuestros días. 
y variadas para los visitantes nacionales y extranjeros. A pesar de lo anterior, hay voces críticas que coinciden en el hecho de que con este tipo de políticas se fomenta la homogeneización y comercialización de sitios en un mercado que "aprecia la cultura" [lo que] provoca que la identidad cultural se difumine lentamente(Equihua, Messina y Ramírez, 2015, p. 5.), lo cierto es que, para el caso de Jala, esta inclusión fue tomada como una oportunidad para trabajar en favor de la conservación, recuperación y difusión de su riqueza cultural, así como para una búsqueda de sus elementos identitarios perdidos. En este contexto, una de las primeras inquietudes que manifestó la autoridad municipal en ese momento fue la de intervenir las fachadas, la gran interrogante ¿bajo qué criterios?

Teniendo a la ciudad como escenario, existen dos planteamientos que permiten estudiar su cromática, una de ellas lo hace desde lo intangible y la otra desde lo tangible; la primera se enfoca a la manera en cómo una persona percibe o recuerda un lugar en particular, evocando aspectos sensoriales, que no necesariamente tienen que coincidir con la realidad, mientras que la segunda, según Lenclos (como se citó en Odetti, Reyes, y Reyes, 2017, p. 57) está basada en la observación metodológica y analítica de varios componentes visuales que contribuyen a la individualización del hábitat. De hecho, esta es la herramienta más práctica para delimitar claramente las tonalidades que constituyen un lugar.

Con respecto a Jala, las discusiones permitieron concluir que, de los dos casos mencionados en el párrafo anterior, el segundo era el más conveniente debido a dos aspectos, uno de ellos tiene que ver con su origen virreinal y la recuperación de uno 
de los atributos más importantes desde el punto de vista de la imagen urbana, nos referimos al colorido que otrora caracterizó a esta villa, y el otro aspecto surge de la necesidad de que se alineen las acciones a ejecutar con el objetivo del ya mencionado programa de Pueblos Mágicos, mismo que se muestra a continuación:

\section{Fomentar el desarrollo sustentable de las localidades poseedoras de atributos de singularidad, carácter y autenticidad a través de la puesta en valor de sus atractivos, representados por una marca de exclusividad y prestigio teniendo como referencia las motivaciones y necesidades del viajero actual (SECTUR, 2014, p. 4).}

De los tres atributos mencionados en el párrafo anterior, muy probablemente el de la "autenticidad" sea el que cobre mayor relevancia, pues éste debe ser el principal hilo conductor que guíe cualquier intervención en inmuebles o áreas patrimoniales. A este respecto, González (1999, p. 22) menciona lo siguiente:

\section{La autenticidad de un elemento o del monumento en su conjunto no se basa tanto en la «originalidad temporal» de la materia o de su naturaleza, como en que sea capaz de autenticar - de «acreditar de ciertos» - los valores del monumento: de documentar los atributos espaciales, mecánicos y formales inherentes a los sistemas constructivos y los elementos ornamentales originales (o, incluso, en ocasiones, las señales, las huellas que la historia y los avatares han dejado en unos y otros), y de permitir la funcionalidad y la significación - estética y emblemática - que unen el monumento a la colectividad.}

Sin lugar a dudas, uno de los valores que mejor puede expresar la autenticidad es el color, cuyo uso ha acompañado al hombre desde tiempos remotos y contribuye a la formación de imaginarios. La importancia del estudio, valoración y rescate de las cromáticas históricas se centra en que, justamente, estos colores tradicionales son principalmente amplificadores de la memoria cultural, mientras que los colores contemporáneos encuentran su referencia en la moda. Los colores locales tradicionales, con los que el individuo es familiar, pueden influir significativamente en la apreciación del paisaje urbano (Zybaczynski, 2014, p. 91).

Derivado de lo anterior, y sobre todo tratándose de estudios de cromática histórica, es importante cuidar las fuentes de información, pues su correcta elección permitirá comprender y justificar toda intervención que se realice en cualquier inmueble o conjunto patrimonial. En ese sentido, la UNESCO (2008, p. 25), menciona que las "fuentes de información" pueden ser definidas como toda fuente física, escrita, oral y figurativa que permite conocer la naturaleza, las especificidades, el significado y la historia del patrimonio cultural. 
Otro aspecto importante a considerar es la escala, ya que admite delimitar el área de estudio, pues no es lo mismo analizar la cromática de un valle a la de un callejón; para este trabajo, el nivel más amplio podría estar representado por el paisaje:

\section{El paisaje está en todos lados, ya que es la imagen que el hombre percibe de su territorio; el paisaje es el único componente del territorio realmente integral, es variado y complejo, ya que incluye formas, tamaños, texturas, colores, luces y sombras, entre otros, que, a través de imágenes, son captadas por el ojo del espectador. (García y Muñoz, como se citó en Tamayo y Ortiz, 2012, p. 34).}

En el caso de Jala, su paisaje está delimitado por el volcán de El Ceboruco -al poniente- y el Cerro de Juanacatlán -al norte y oriente-, ambos con más de 2,000 m.s.n.m., mientras que el emplazamiento urbano, y la zona con la que colinda al sur, corresponden a una llanura aluvial (INEGI, 2009, p. 5).

En un orden descendente, el siguiente nivel lo determina una sección de este paisaje, pudiendo ser, por ejemplo, aquella que coincide con las trazas antiguas de pueblos y ciudades; zonas de este tipo son estudiadas recientemente bajo nuevos conceptos, uno de ellos, quizá el más aceptado, es el que maneja la UNESCO (como se citó en Sepúlveda, 2017, p. 146):

Si trasladamos la definición anterior a Jala, tenemos que el polígono que actualmente se conoce como Centro Histórico se ajusta perfectamente al alcance establecido en el párrafo que antecede, ya que abarca buena parte de sus tres barrios tradicionales -San Francisco, San Juan y de la Natividad-, y concentra la mayor parte de las actividades sociales, culturales y económicas, además de incluir a la mayoría de los inmuebles con valor patrimonial, cuya datación va desde el siglo XVII hasta el primer tercio 
del siglo XX; la base legal de este polígono está determinada por el "Plan Parcial de Conservación para el Centro Histórico de Jala, Nayarit" (2004), y su correspondiente "Declaratoria de Inmuebles del Patrimonio Histórico, Artístico y Cultural del Centro y Municipio de Jala, Nayarit" (2005), y es el que se muestra en la figura 2.

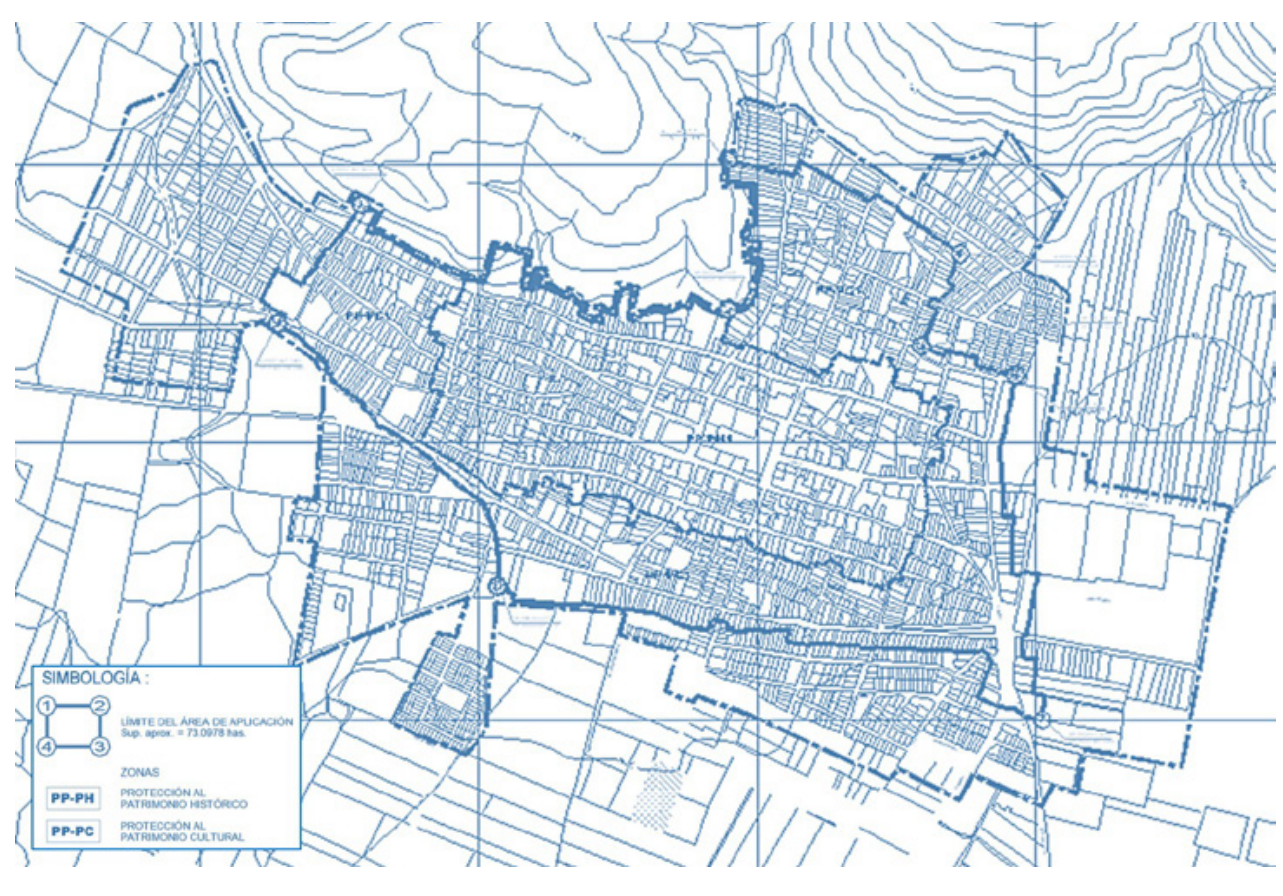

Figura 2. Polígono del Centro Histórico de Jala. Fuente: Plan Parcial de Conservación para el Centro Histórico de Jala. 
Una vez que las autoridades locales contaron con los recursos provenientes del Programa de Pueblos Mágicos -año 2013-, se pensó en llevar a cabo la intervención de las fachadas ubicadas en torno a la Plaza Principal, así como en aquellas localizadas a lo largo de las calles que van desde el ingreso hasta el Centro Histórico; el objetivo inicial del Ayuntamiento fue pintar el frente de estas edificaciones con predominancia de colores partidistas, lo cual fue rechazado por las instancias del Gobierno Federal que son competentes tanto en materia de conservación del patrimonio como en la promoción del turismo; en consecuencia, se tuvieron que buscar otras opciones que sí fueran factibles, iniciativas más incluyentes y que vinieran a generar una resignificación y revaloración del patrimonio edificado, sin perder de vista los ya mencionados atributos de singularidad, carácter y autenticidad; una de estas opciones se centró en llevar a cabo un inventario de la cromática existente, con el objeto de determinar una paleta que concentrara los colores que la actual generación de jalenses emplea para sus viviendas; otra alternativa planteada fue la de buscar vestigios físicos y documentales de los tonos usados en los inmuebles históricos en tiempos pretéritos, llegándose a la conclusión de que esta última era la opción más viable.

Para lograr ese objetivo, fue necesario conformar un equipo multidisciplinario e interdisciplinario, y elaborar una propuesta metodológica diseñada para la conformación de una paleta de colores específica para el Centro Histórico de Jala, cuya estructura básica está compuesta por los siguientes pasos:

1. Determinación del área de estudio.

2. Ubicación de inmuebles en los que se presume podrían existir restos de pintura histórica.

3. Realización de calas exploratorias.

4. Búsqueda de información documental, gráfica y oral de los criterios empleados en tiempos pretéritos para la aplicación de color.

5. Contrastación de la información obtenida en los puntos 3 y 4.

6. Conformación de la paleta cromática definitiva.

7. Socialización de dicha paleta cromática.

8. Intervención de las fachadas.

Teniendo al Centro Histórico de Jala como área de estudio, se seleccionaron aquellos inmuebles en los que se tuviera la posibilidad de encontrar vestigios de pintura. Habiendo definido lo anterior, las actividades iniciarían en ese mismo año de 2013 y correrían a cargo del personal de las Áreas de Conservación y de 
Monumentos Históricos del Centro INAH Nayarit, quienes, junto con tres estudiantes de la ENCRyM, llevaron a cabo diversas actividades, las cuales incluyeron la realización de calas estratigráficas en las fachadas históricas seleccionadas previamente, en las cuales se tuviera la posibilidad de encontrar aplanados antiguos, o policromías que fueran anteriores a la primera mitad del siglo XX. Una cala, o cata, es aquel procedimiento exploratorio hecho para descubrir en muros o pavimentos la presencia de pinturas o cualquier otro dato que permita reconocer una etapa anterior [ya sea decorativa o] de construcción en el edificio (Consejo Regional Adopte una Obra de Arte Tepic, A.C., 2011, p. 147).

Llevar a cabo este ejercicio tuvo como propósito el verificar la existencia de colores anteriores a la época en la cual las fachadas de Jala estuvieron pintadas en dos colores, blanco en sus muros y rojo en los ornamentos y guardapolvos, tal y como sucedió en otras localidades del país; vale la pena recordar que, en México, la creación de centros rojo colonial siguió a la moda del blanco de los años sesenta y setenta (Melé, 2006, p. 97). Tras la conclusión de la elaboración de las calas exploratorias, Gallo (2013, pp. 2-3) menciona lo siguiente:

\begin{abstract}
Los resultados obtenidos tras la realización de dichas calas no permitieron obtener una muestra completa de las capas de pintura debido al mal estado de conservación en que se encontraban. Sin embargo, de manera general, fue posible distinguir la aplicación de entre tres y cuatro capas de pintura por inmueble [...] La paleta cromática en este sentido responde a colores obtenidos de tierras naturales, tales como rojo óxido, ocres e incluso algunas tonalidades en colores pastel, como rosa palo, azul cielo o violeta, entre otros.
\end{abstract}

Paralelamente, se consultó al cronista local, Miguel González Lomelí, quien informó que en 1967, en el marco del 50 aniversario de Nayarit como estado Libre y Soberano ${ }^{4}$, el Gobernador de entonces, Julián Gascón Mercado, ordenó que se llevaran a cabo estudios que permitieran documentar los aspectos más importantes de algunas de las poblaciones de la entidad, principalmente de las cabeceras municipales; acerca de Jala, se destacó el predominio del color blanco de sus fachadas, seguramente por estar encaladas, lo cual se pudo comprobar a través de la consulta de acervo fotográfico disponible en la red y del resultado arrojado por las calas exploratorias.
${ }^{4}$ El Estado de Nayarit fue elevado a la categoría de estado libre y soberano con la promulgación de la actual Constitución Política de los Estado Unidos Mexicanos, el 5 de febrero de 1917, quedando estipulado en el Artículo 47 que el Estado del (sic DOF 05-02-1917) Nayarit tendrá la extensión territorial y límites que comprende actualmente el Territorio de Tepic. 
La información obtenida en ambos ejercicios, es decir, tanto la evidencia física como la consulta de fuentes documentales, gráficas y orales, permitió elaborar una propuesta de recuperación de la cromática histórica, combinando ambos criterios, o sea, emplear el color blanco para los macizos -muros-, mientras que, para los ornamentos y guardapolvo, optar por alguno de los colores obtenidos con las mencionadas calas (Ver figura 3).
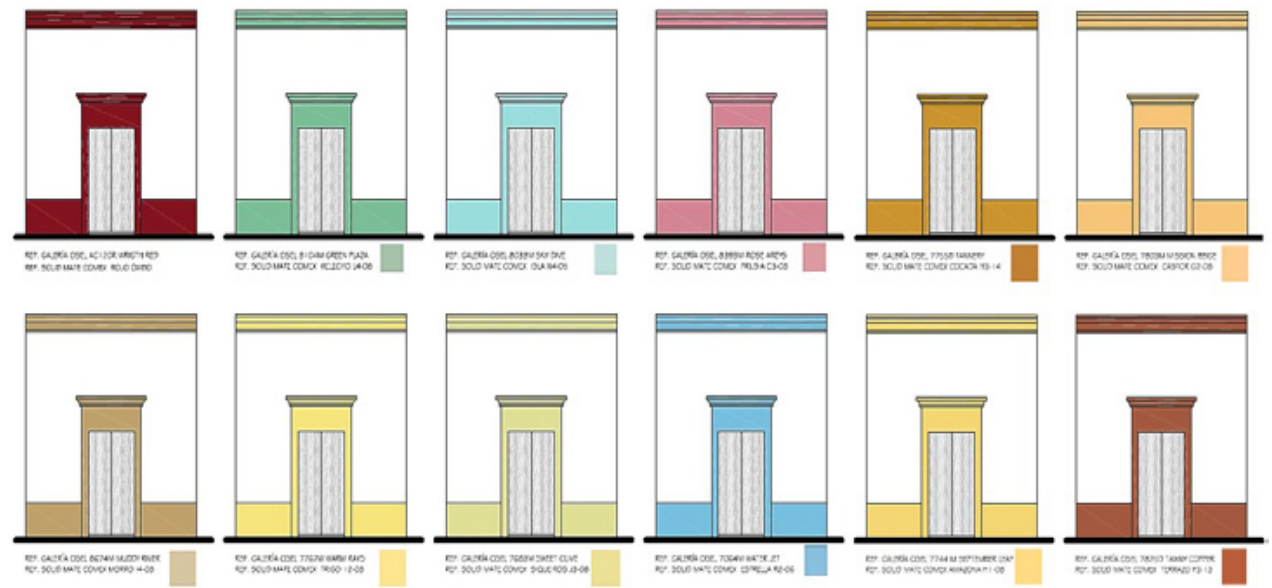

Figura 3. Propuesta cromática para las fachadas del Centro Histórico de Jala. Fuente: Centro INAH Nayarit. 


\section{Los alcances y resultados.}

Después de haber concluido con la parte técnica, y teniendo la cromática definida ${ }^{5}$, se estaba en condiciones de iniciar con la parte social, es decir, la concertación. Esta labor se desarrolló de manera conjunta entre personal del Centro INAH Nayarit, en coordinación con la extinta Secretaría de Desarrollo Social -hoy Secretaría del Bienestar-, a través del Programa de Empleo Temporal-PET-, además del Ayuntamiento local, convocando a las personas propietarias de las fincas que se encontraban en las dos áreas de actuación: la primera correspondió a las viviendas ubicadas en la calle Tampico, entre calle Abasolo y calle Morelos, y la segunda a las situadas en la calle Morelos, entre calle Tampico y calle Morelia. La gente convocada fue informada acerca del alcance del proyecto, así como haciendo de su conocimiento que sería sin costo alguno para ellas, pues todos los gastos serían cubiertos como parte del PET, es decir, por las tres Dependencias involucradas. Vale la pena aclarar que en todo momento se respetó la decisión que tomaron tanto las personas que aceptaron, que fueron la gran mayoría, como aquellas que decidieron no participar. Teniendo claro lo anterior, a finales del año 2013, se realizaron las primeras acciones de mantenimiento en fachadas, logrando beneficiar a gente de la localidad para que fueran ellas mismas quienes procedieran a ejecutar los trabajos, dotándoles de los materiales y equipo necesarios, así como recibiendo una remuneración semanal por ello. Un año después, serían los gobiernos locales, tanto del Estado como del Municipio, los que darían continuidad al proyecto, fijándose dos etapas de intervención más, en las que se incluyeron varias calles del Centro Histórico.

En todos los casos, para la asignación del color se fijaron dos criterios: para aquellas viviendas en las que se encontró algún vestigio de color, éste se mantendría, mientas que para aquellas en las que no hubiera sido así, la asignación sería al azar, procurando alternar los colores, con el objeto de evitar el predominio de alguno en particular.
${ }^{5}$ Cabe mencionar que este trabajo académico de recuperación cromática a nivel de Centro Histórico, es único en su tipo en el estado de Nayarit, y es, quizá, uno de los pocos que se han hecho en México a ese nivel, de ahí la importancia de su aplicación y valoración. 
Los trabajos incluyeron la eliminación de vegetación parásita, liberación de aplanados deteriorados, sueltos y/o en mal estado, liberación de pintura en mal estado, integración de rajuela en muros de adobe, restitución de aplanados perdidos, reperfilado de molduras, aplicación de pintura en muros y elementos metálicos de la fachada y limpieza general, conceptos aplicados según los requerimientos de cada vivienda (ver figura 4 ).

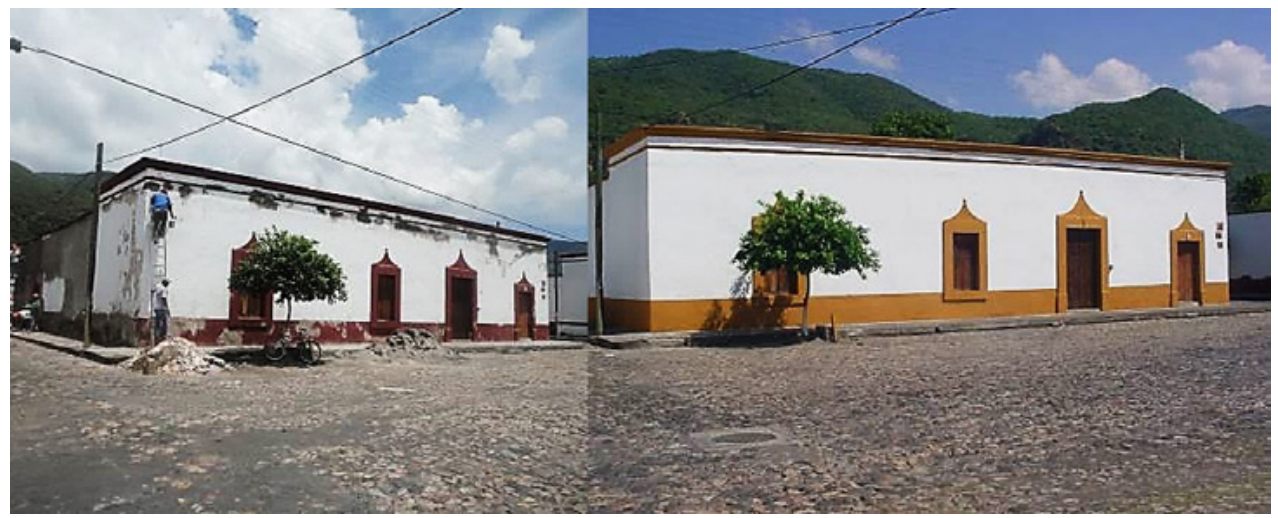

Figura 4. Antes y después del proceso de mantenimiento en fachadas. Fuente: Centro INAH Nayarit.

A finales del año 2019, la autoridad municipal decidió retomar el tema de mejorar la imagen urbana del Centro Histórico, para lo cual nuevamente se seleccionó el área que se había trabajado seis años atrás; después de un proceso de análisis y discusión, se acordó que se retomaría la cromática histórica recuperada en el año 2013, con la diferencia de que, en esta ocasión, se incluirían elementos de mobiliario urbano, vegetación y señalética (Ver figura 5) y se espera que estos sirvan como criterios a seguir para las futuras intervenciones en las demás calles de la localidad. 


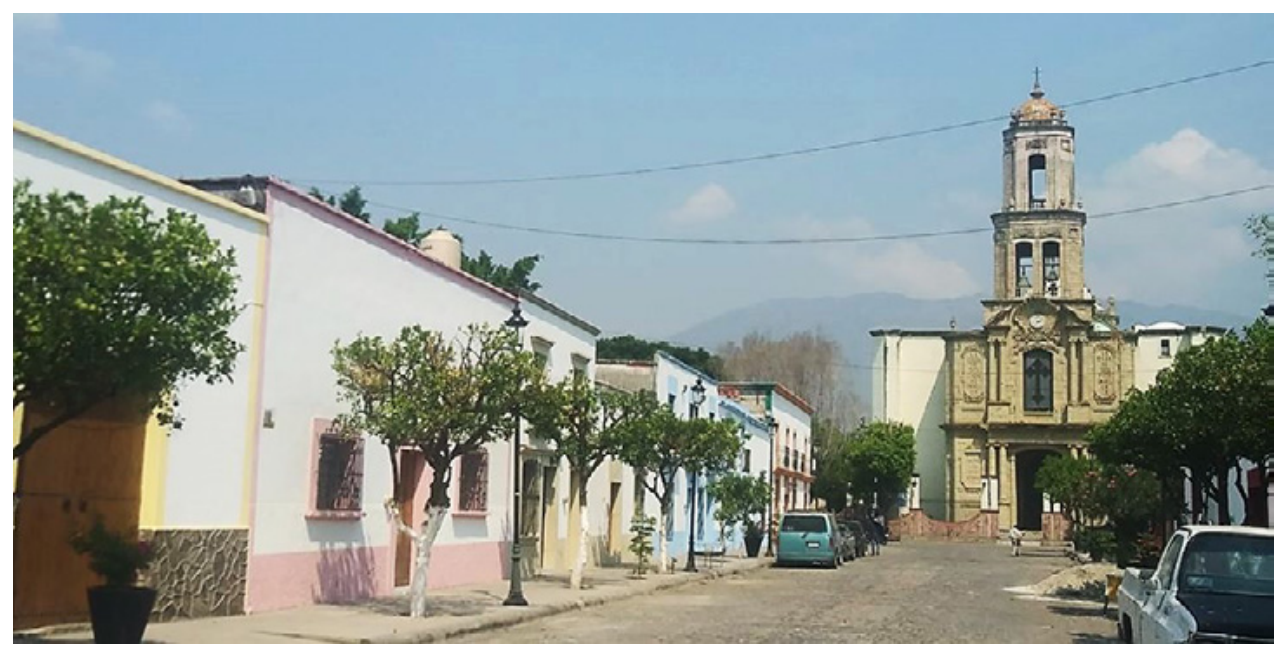

Figura 5. Vista General de Jala en la actualidad.

Fuente: autor.

\section{CONCLUSIONES}

Si bien es cierto, este ejercicio se ha considerado como exitoso debido al alto nivel de aceptación manifestado entre los habitantes de la localidad, interpretándose esto como un síntoma de revaloración de su patrimonio edificado a través de la recuperación de su cromática histórica, no hay que perder de vista la situación económica desfavorable prevaleciente, la cual podría haber influido en esta aceptación.

Independientemente de lo anterior, lo que se considera como un gran acierto fue el haber involucrado a la ciudadanía en cada una de las etapas planeadas, tomando decisiones colegiadas, y discutiendo los temas necesarios, para que, de esta manera, cualquier acción que se vaya a emprender cuente con el respaldo de todos los involucrados, facilitando su implementación, ya que se entenderá como el resultado de un proceso de reflexiones, y no de imposiciones. 
El privilegiar al habitante de la localidad tendrá que prevalecer sobre cualquier estrategia turística y/o económica que se pretenda seguir en Jala. Más aún cuando allí se ha decidido aprovechar el potencial de su paisaje cultural para consolidarlo como un destino turístico competitivo, y ser una opción alterna al turismo de sol y playa que ha caracterizado a Nayarit en los años recientes. El lograr lo anterior requerirá tener en cuenta aspectos como la capacidad de carga turística, garantizando con ello la permanencia de sus atributos culturales y ambientales.

Como ya se ha comentado, este trabajo de recuperación de cromática histórica es caso único en el estado de Nayarit, y tuvo como base el diseño de una metodología hecha a la medida de Jala, pero lo suficientemente bondadosa como para ser reproducida en otras localidades con características similares, en beneficio de la investigación, protección, conservación, restauración y recuperación de los monumentos históricos y de las zonas de monumentos, pero sobre todo, en el redescubrimiento y revalorización de la arquitectura tradicional y de los aspectos que le son inherentes, como es el caso del color, dejando de ser consideradas como simples casas viejas de adobe, para formar parte viva y significativa del patrimonio histórico; estas edificaciones representan atributos culturales de momentos diversos que testifican aspectos económicos, políticos y sociales que permiten, a la vez, volver a hacer presentes tiempos pretéritos, pero con proyección hacia el futuro, con el objeto de que sirvan para el disfrute de ésta y de las generaciones venideras. 


\section{REFERENCIAS BIBLIOGRÁFICAS}

Consejo Nacional de Evaluación de la Política de Desarrollo Social (2015). Medición de la pobreza, Nayarit, 2010-2015. Indicadores de pobreza por municipio. Recuperado de: https://www.coneval.org.mx/ coordinacion/entidades/Nayarit/Paginas/pobreza_municipal2015.aspx.

Consejo Nacional de Evaluación de la Política de Desarrollo Social (s.f.). La medición multidimensional de la pobreza en México. Ciudad de México: CONEVAL.

Consejo Regional Adopte una Obra de Arte Tepic, A.C. (2011). El tiempo sobre la piedra. Historia y arte en el Panteón Hidalgo de Tepic. Guadalajara: Impre-Jal.

Constitución Política de los Estados Unidos Mexicanos. Diario Oficial de la Federación, Ciudad de México, México, 5 de febrero de 1917.

Declaratoria de Inmuebles del Patrimonio Histórico, Artístico y Cultural del Centro y Municipio de Jala, Nayarit. Periódico Oficial del Gobierno del Estado de Nayarit, Tepic, 09 de abril de 2005.

Equihua, G., Messina, S. y Ramírez, J. (2015). Los Pueblos Mágicos: una visión crítica sobre su impacto en el desarrollo sustentable del turismo. Revista Fuente. 22. pp, 1-7. Recuperado de: http://aramara. uan.mx:8080/handle/123456789/1114.

Gallo, D. (2013). Reporte en relación a las calas estratigráficas realizadas en las fachadas de diversos inmuebles históricos en la cabecera municipal de Jala, Nayarit. Tepic: INAH.

García, N. (1997). El patrimonio cultural de México y la construcción imaginaria de lo nacional. En Florescano, Enrique (coord.). El patrimonio nacional de México (pp. 57-86, t. I). México: CONACULTA y FCE.

González, A. (1999). La restauración objetiva. Método SCCM de restauración monumental. Memoria SPAL 1993-1998. Barcelona: Diputación de Barcelona. Área de Cooperación. Servicio de Patrimonio Arquitectónico.

González, J. (2019). El elote más grande del mundo es nayarita. Recuperado de: https://www.unotv.com/ noticias/estados/nayarit/detalle/elote-mas-grande-del-mundo-nayar-952337/.

González, M. (2009). Xala, un pueblo, un destino. Tepic: Fondo Estatal para la Cultura y las Artes de Nayarit.

Instituto Nacional de Antropología e Historia. (1994). Catálogo de Monumentos Históricos. Jala. México: Coordinación Nacional de Monumentos Históricos, INAH. 
Instituto Nacional de Estadística, Geografía e Informática. (2009). Prontuario de información geográfica municipal de los Estados Unidos Mexicanos. Jala, Nayarit. Aguascalientes: INEGI.

Instituto Nacional de Estadística, Geografía e Informática. (2018). Mapas para imprimir. Nayarit. Recuperado de: http://cuentame.inegi.org.mx/mapas/pdf/entidades/div_municipal/nayarit.pdf.

Ley Orgánica de la Administración Pública Federal. Diario Oficial de la Federación, Ciudad de México, 29 de diciembre de 1976.

Lira, R. (2004). Patrimonio Urbano. Urbano, 7(10),0. ISSN: 0717-3997. Recuperado de: https://www.redalyc. org/articulo.oa?id=198/19871001

Melé, P. (2006). La producción del patrimonio urbano (pp. 77-122). México: CIESAS.

Odetti, J., Reyes, A. y Reyes, A. (2017, enero 31). El diseño cromático como propuesta de revalorización de la imagen urbana: el caso de Puerto Vallarta, México. Zincografía, volumen (1), pp. 52-71.

Organización de las Naciones Unidas para la Educación, la Ciencia y la Cultura. (1972). Convención sobre la Protección del Patrimonio Mundial Cultural y Natural 1972. Recuperado de: http://portal.unesco.org/es/ ev.php-URL_ID=13055\&URL_DO=DO_TOPIC\&URL_SECTION=201.html.

Organización de las Naciones Unidas para la Educación, la Ciencia y la Cultura. (2008). Directrices prácticas para la aplicación de la Convención del Patrimonio Mundial. París: Centro del Patrimonio Mundial de la UNESCO.

Patrimonio (2014). En el Diccionario de la Real Academia Española. (23a ${ }^{a}$ Ed.). Recuperado de: https://dle.rae. es/patrimonio? $\mathrm{m}=$ form. 
Pereira, N. (2013, diciembre 10). La luz y el color. Recuperado de: https://www.elcorreogallego.es/opinion/ ecg/nuria-pereira-luz-yel-color/idEdicion-2013-08-15/idNoticia-821899/.

Plan Parcial de Conservación para el Centro Histórico de Jala. Periódico Oficial del Gobierno del Estado de Nayarit, Tepic, 01 de diciembre de 2004.

Samaniega, F. (2004). Historia General de Jala. Tepic: El Nayarit Editorial.

Servicios de Educación Pública en el Estado de Nayarit. (s.f.a). Efemérides. Diciembre. Recuperado de: http:// www.sepen.gob.mx/infed/efemerides/Diciembre.pdf.

Servicios de Educación Pública en el Estado de Nayarit. (s.f.b). Efemérides. Julio. Recuperado de: http:// www.sepen.gob.mx/infed/efemerides/Julio.pdf.

Secretaría de Turismo. (2014). Guía de incorporación y permanencia. Pueblos Mágicos. Ciudad de México: SECTUR.

Secretaría de Turismo. (2019). Pueblos Mágicos. Recuperado de: https://www.gob.mx/sectur/ acciones-y-programas/pueblos-magicos-de-mexico-206647.

Sepúlveda, Sebastián. (2017). Estado del arte sobre centros históricos en ciudades mexicanas. En Pineda, Alma y Velasco, Mauricio (coord.). Ciudades y Centros Históricos. Los retos de la vivienda y la habitabilidad (vol. I, pp. 133-167). México: PUEC, UNAM, CONACYT y Universidad de Guanajuato.

Tamayo, L. y Ortiz, M. (2012). Los centros históricos desde la perspectiva del paisaje (pp. 33-40). En Ortiz Álvarez, María Inés y Tamayo Pérez, Luz María Oralia (coord.). El paisaje en los centros históricos. Un legado cultural y perspectivas para su conservación en México y España. México: Instituto de Geografía, UNAM.

Vite, V. (2011). Análisis histórico de las etapas constructivas del inmueble (pp.1-40). En Secretaría de Obras Públicas del estado de Nayarit. Capilla de San Francisco y de la Inmaculada Concepción. Proyecto de restauración. Tepic: Secretaría de Obras Públicas del Estado de Nayarit.

Zybaczynski, V. (2014). Colour - important factor in preserving the local identity [Color-factor importante en la preservación de la identidad local]. Recuperado de: https://uac.incd.ro/Art/v5n4a12.pdf 